\title{
Descartes' dogma and damage to Western psychiatry
}

\author{
A. Ventriglio ${ }^{1}$ and D. Bhugra ${ }^{2 *}$ \\ ${ }^{1}$ University of Foggia, Foggia, Italy \\ ${ }^{2}$ Institute of Psychiatry, Psychology \& Neuroscience, King's College London, London, UK
}

René Descartes described the concept of mind-body dualism in the 16th century. This concept has been called his error but we prefer to call it his dogma because the error was recognised much later. We studied the original writings translated by various scholars. We believe that his dogma has caused tremendous amount of damage to Western psychiatry. This dualism has created boundaries between mind and body but as we know they are inextricably interlinked and influence each other. This has affected clinical practice and has increased the dichotomy between psychiatric services and the physical health care services in the West at least. This dualism has also contributed to stigma against mental illness, the mentally ill and the psychiatric services. We propose that it is time to abandon this mind-body dualism and to look at the whole patient and their illness experiences as is done in some other health care systems such as Ayurveda.

Received 2 March 2015; Accepted 1 July 2015

Key words: Diagnosis, history of psychiatry, models/theories of psychiatry, social and political issues.

\section{Introduction}

For centuries, psychiatric patients were known as aliens and psychiatrists were described as alienists. These terms meant that individuals who developed mental illness were seen as outsiders and, when asylums were set up, these institutions were often based outside cities in isolated places. This distinction was probably influenced by a number of factors: as possession states, as a result of stigma and perhaps development of institutions as a variant of sanatoria for tuberculosis and other infectious diseases. The causative factors of mental illness were seen as both exogenous and endogenous (Hunter \& McAlpine, 1963). The treatment often included containment and, in the past two centuries, various physical restraints and interventions began to emerge.

In this commentary, we highlight the impact the French philosopher René Descartes had on Western psychiatry and psychiatric practice, and what we need to do to overcome this.

\section{Descartes' dogma}

Dogma is a principle or set of beliefs and principles and it is fair to call Descartes' position as dogma as people have continued to believe in it irrespective of the evidence contrary to it. Descartes split the mind from the brain and the body (Descartes, 1970).

\footnotetext{
* Address for correspondence: D. Bhugra, Emeritus Professor, Institute of Psychiatry, Psychology \& Neuroscience, King's College London, London, UK.

(Email: dinesh.bhugra@kcl.ac.uk)
}

Descartes (Descartes, 1998) argues that 'I can obtain some knowledge of myself without knowledge of the body' (p. 143). Herein lies the rub. Although he goes on to say that he may not be aware of everything in his body but that he was supposing that he was not aware that the mind possessed the power of moving the body. This is a clear indication that he is seeing mind and body as two separate 'things'. Descartes notes that after careful consideration he made a clear distinction between the idea of mind and the idea of body and corporeal motion and was really confident that he had a clear idea of mind (Descartes, 1998, pp. 148-149), interestingly the soul is united conjointly to the whole body. For the body is a unity, Descartes argues, which is in a sense indivisible because of the arrangement of its organs, these being so related to one another that the removal of any one of them renders the whole body defective (Descartes, 1998, pp. 229). He sees soul as of being of such nature that it has no relation to extension, or to the dimensions or other properties of the matter of which the body is composed: it is related solely to the whole assemblage of the body's organs. Thus there is a further clearer distinction between soul, mind and body. Damasio (1999) argues very persuasively that Descartes convinced biologists to adopt to this day clockwork mechanics as a model for life processes (p. 248). Damasio notes that Descartes' statement that 'I think therefore I am' (cogito ergo sum) suggests that thinking and awareness of thinking are the real substances of being. Thus as Descartes saw thinking as part of the brain, the body became non-thinking. The body thus had mechanical non-thinking parts and function. 
Damasio (1999) notes that 'Descartes' error is the abysmal separation between body and mind, between the sizable, dimensioned, mechanically operated infinitely divisible body stuff, on the one hand; and un-sizable, unidimensional, un-push/pullable, non-divisible mind stuff' (pp. 249-250). Descartes in a way followed Plato's views (Hamilton \& Cairns, 1971). In addition, Descartes thought that fine particles of blood were animal spirits which could move muscles. Although this theory was subsequently discredited after the discovery of circulation, mind-body dualism seemed to persist. It can be argued that Descartes developed his theories at the instigation of the church, which maintained that soul and mind belonged to the church, whereas doctors could have the body, but the evidence is not clear. Damasio (1999) seems to take the view that this may have been the case, but there is no way to confirm that (p. 249). Harrington (2008) notes that it was Descartes who with his notorious philosophy of mind-body dualism launched medicine on the path towards its current unsatisfying vision of human mind-body relationships (p. 20). She also, like Damasio, questions whether the church had anything to do with the control. In some ways, it can be argued that the Church wanted to keep control of the soul and the mind leaving body to the attention of doctors.

For a considerable period the religion and its impact on the individual functioning was paramount. The tension between mind and brain has become much more prominent in recent times as functioning of brain is increasingly being understood better.

This dichotomy put simply means that there appears to be no connection between mind and body and as if they work in totally separately spheres. This obviously is not the case and this dogma outlined by Descartes continues to plague modern medicine as well as psychiatry. It is perhaps worth comparing the Cartesian model with other models. We suggest that stigma against mental illness is related to a lack of knowledge and mystery that surrounds mental illness and also because those with mental illness were isolated from the society in asylums and institutions. Similar attitudes were seen at the time of AIDS epidemic.

\section{Other health care systems}

We will very briefly outline the health care according to the Ayurvedic system. We are most familiar with this system (of Ayurveda) so can confidently argue that the basic tenets of this system include a much more holistic approach in combining a number of aetiological and management factors. Developed and outlined millennia prior to modern allopathic system, this Hindu system (literally meaning knowledge of long life) (Caraka Samhita, 1949) provides an overview, classification and aetiological and management factors of physical and mental disorders. To outline very basic general principles, the Ayurvedic system proposes that illnesses, whether physical or mental, are caused by a number of factors, including weather, climate, physical circumstances, diet, taboos, relationships, etc. (Bhugra, 1992). Thus a holistic picture starts to emerge where truly biological (organic) or physiological factors; social factors and personality factors all play a key role in the genesis and subsequent management of all disorders. This allows multiple approaches to be used in diagnosing and managing illnesses. It would appear that such approaches have not been affected by Cartesian mind-body dualism, and the whole person is seen as being affected by a number of factors. Other health care systems have similar approaches.

\section{Dogma causing damage}

Cartesian mind-body dualism has created major problems for Western medicine, as well as for Western psychiatry. This has meant that both aetiologically and management wise, there has been a clear divide between mind and body. This divide has caused structural and functional challenges to Western psychiatry. Psychiatric services often exist separately from physical care. Secondly, within medicine there appears to be a general assumption that physicians and surgeons do not need to know about mind or mental functions, as these fall into the prerogative of psychiatrists. Thirdly, by and large psychiatrists tend to ignore physical aspects of care of their patients, even though first and foremost psychiatrists are doctors. These divisions are further complicated by the fact that resources for mental health services lag behind need. The funding crises in Western Europe in psychiatric services reflect the Cartesian dualism and dogma. Stigma related to ignorance has contributed to inequity in funding for research and service funding. It may not be Descrates' fault per se but the role of the mindbody dualism cannot be ignored in this. It is crucial that funders are reminded that burden due to mental illness is greater than that caused by cancer or heart disease. Furthermore, the fact that those with mental illness die 15-20 years younger than those who do not have a mental illness (Ventriglio \& Bhugra, 2015) reflects this dogma and resulting discrimination. It is interesting to note that in many parts of Western Europe the role and resulting impact of the church is diminishing, but somehow the church influenced Cartesian dichotomy continues to pervade our clinical practice. 


\section{Dumping the dogma}

The first step in dumping or dodging this dogma is that we must recognise that mind-body dualism is false. The mind affects the body, and the body affects the mind. As a result of this dichotomy, some psychiatrists (Leff, 1984) have argued that patients who somatise are somehow inferior psychologically, not understanding the fact that these individuals may not be following traditional models of mind-body dualism.

The abandonment of this faux dualism is the first step in our training of physicians, including psychiatrists. Integration of training, funding and service development is crucial. In a recent enquiry (Carlisle \& Bhugra, 2013), integration between physical and mental health, between social and mental health care and between primary and secondary care was recommended. If such a physical integration is not possible, then at least an emotional integration is indicated. The interconnectedness between brain and body as is being updated regularly confirms that the damage caused by Descartes has lasted 400 years, and it is time to dump this. As his theories on blood and microparticles were discredited, the impact of body on brain functioning and vice versa must lead to a total abandonment of mind-body dualism. That is not to say that brain and mind are the same but, as Damasio (1999) points out, versions of Descartes' error obscure the roots of the human mind in a biologically complex but fragile, finite and unique organism (p. 251). Mind may be abstract and although compared with software with the brain as hardware, we believe that mind goes beyond the software analogy.

Both clinicians and researchers need to develop models which integrate physical and mental illnesses. First step may well be the false dichotomy in funding for research needs to disappear. Every physical condition must include mental health implications. Secondly there needs to be better integration between physical and mental illness in service provision. There have been concerns that such an integration may well be at the expense for funding of mental health services but models exist where funding for mental health services is ring-fenced in perpetuity. In addition, comparison with other systems, such as Greek or Chinese system of medicine are important in developing a holistic service where physical and mental health are truly integrated.

\section{Conflict of Interest}

None.

\section{Financial support}

This research received no specific grant from any funding agency, commercial or not-for-profit sectors.

\section{References}

Bhugra D (1992). Psychiatry in ancient Indian texts: a review. History of Psychiatry 3, 167-186.

Caraka Samhita (1949). Shree Gulals Kunverba Ayurvedic Society: Jamnagar.

Carlisle L, Bhugra D (2013). Future of Mental Health Services. Mental Health Foundation: London.

Damasio A (1999). Descartes' Error: Emotion, Reason and the Human Brain. Vintage: London.

Descartes R (1970). The Philosophical Works of Descartes (1637). Cambridge University Press: Cambridge.

Descartes R (1998). Selected Philosophical Writings. Cambridge University Press: Cambridge.

Hamilton E, Cairns H (ed.) (1971). Phaedo: The Collected Dialogues of Plato. Pantheon Books: New York.

Harrington A (2008). The Cure Within. W W Norton: New York.

Hunter R, McAlpine I (1963). Three Hundred Years of Psychiatry. pp. 1535-1868. Oxford University Press: Oxford.

Leff J (1984). Psychiatry around the Globe. Gaskell: London.

Ventriglio A, Bhugra D (2015). Social Justice for the mentally ill. International Journal of Social Psychiatry 61, 213-214. 